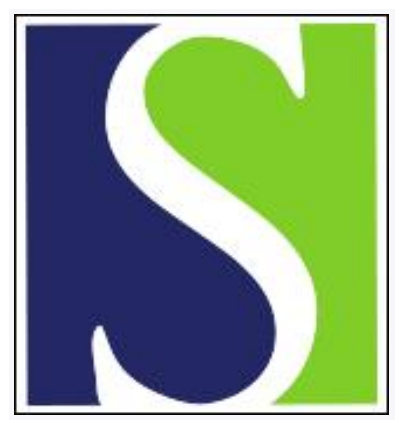

Scand J Work Environ Health 2005;31(1):30-35

https://doi.org/10.5271/sjweh.845

Issue date: Feb 2005

Total mortality and cause-specific mortality of Swedish shiftand dayworkers in the pulp and paper industry in 1952-2001

by Karlsson B, Alfredsson L, Knutsson A, Andersson E, Torén K

Affiliation: Department of Public Health and Clinical Medicine, Occupational Medicine, University of Umeå, SE 901 85, Sweden. bernt.karlsson@vll.se

The following articles refer to this text: 2007;33(6):435-439; 2007;33

suppl 1:1-53; 2007;33(6):470-478; 2008;34(3):198-205;

2009;35(3):163-179; 2009;35(4):309-318; 2010;36(2):109-121;

2010;36(2):150-162; 2012;38(4):337-342; 2015;41(3):288-293;

2017;43(2):117-126; 2020;46(5):508-515; 2022;48(1):31-40

Key terms: age-standardized rate ratio; cause-specific mortality; cohort; coronary heart disease; dayworker; diabetes; pulp and paper industry; shiftworker; stroke; Sweden

This article in PubMed: www.ncbi.nlm.nih.gov/pubmed/15751616 


\title{
Total mortality and cause-specific mortality of Swedish shift- and dayworkers in the pulp and paper industry in 1952-2001
}

\author{
by Berndt Karlsson, MD, ${ }^{1}$ Lars Alfredsson, PhD, ${ }^{2}$ Anders Knutsson, MD, ${ }^{3}$ Eva Andersson, MD, ${ }^{4}$ Kjell \\ Torén, $M D^{4}$
}

\begin{abstract}
Karlsson B, Alfredsson L, Knutsson A, Andersson E, Torén K. Total mortality and cause-specific mortality of Swedish shift- and dayworkers in the pulp and paper industry in 1952-2001. Scand J Work Environ Health 2005;31(1):30-35.
\end{abstract}

\begin{abstract}
Objectives The study investigated the relationship between shiftwork and mortality, both total mortality and cause-specific mortality from coronary heart disease (CHD), stroke, and diabetes.

Methods The cohort consisted of 2354 shiftworkers and 3088 dayworkers in two pulp and paper manufacturing plants. The mortality of the cohort was monitored from 1 January 1952 to 31 December 2001 by linkage to the national Cause of Death Register. Groups of workers defined by different durations of shiftwork exposure were compared with dayworkers by calculating standardized relative rates (SRR).

Results Death due to any cause (total mortality) was not higher among the shiftworkers than among the dayworkers [SRR 1.02, 95\% confidence interval (95\% CI) 0.93-1.11]. A longer duration of shiftwork was associated with an increased risk of CHD, and shiftworkers with $>30$ years of shiftwork had the highest risk of CHD (SRR 1.24, 95\% CI 1.04-1.49) Diabetes was more common as the number of shift years of exposure increased $\left[\mathrm{b}(\right.$ linear coefficient $)=4.14 \times 10^{-5}, 95 \%$ CI $\left.2.46 \times 10^{-5}-5.81 \times 10^{-5}\right]$. Compared with dayworkers, shiftworkers had a greater risk of death due to stroke (SRR 1.56, 95\% CI 0.98-2.51).

Conclusions In the present study, no general increase in mortality was observed among shiftworkers when they were compared with dayworkers. However, the results demonstrate an increased mortality from CHD among shiftworkers with a long duration of shiftwork exposure. Mortality due to diabetes also increased as the number of shift years and mortality due to ischemic stroke in shiftworkers increased.
\end{abstract}

Key terms age-standardized rate ratio; cohort; coronary heart disease; diabetes; stroke.

Shiftworkers seem to have more health problems than dayworkers. They have more sleep disorders (1), gastrointestinal problems (2), and cardiovascular disease (3). However, few studies have investigated general mortality among male shiftworkers. Taylor \& Pocock (4) followed a cohort of 8603 male workers between 1956 and 1968 and concluded that shiftwork had no adverse effect on general mortality. Bøggild et al (5) reported similar results in a Danish cohort study of 4804 day- and 1123 shiftworkers who were followed for 22 years. Both of these studies were based, however, on uncertain data on shiftwork exposure. Taylor \& Pocock's study can also be criticized for using indirect standardization for age adjustment. Indirect standardization is not suitable for internal comparisons in many groups because different age weights are used for the groups.

In our present study, we followed a historical cohort of male paper and pulp manufacturing workers. Company registers gave us good access to accurate information on exposure to shiftwork. The aim of the study was to investigate the relationship between shiftwork and total mortality and also between shiftwork and mortality due to coronary heart disease (CHD), stroke, and diabetes by comparing the mortality of shiftworkers with that of dayworkers. 


\section{Study population and methods}

\section{Study population}

The study population consisted of male workers from two pulp and paper manufacturing plants owned by the same company in the north of Sweden. Both plants had stored company files regarding present and previous employees. These files made it possible to identify a study population defined as blue-collar workers who had been employed for at least 6 months between 1 January 1940 and 31 December 1998. Production line supervisors were normally recruited from the blue-collar group and were regarded as blue-collar workers.

A total of 5696 persons were identified. Eighty persons with incomplete information about job history, 39 men who were older than 60 years at age of first employment, and 135 persons who were not possible to trace were all excluded. The remaining persons, consisting of 2354 shiftworkers and 3088 dayworkers, were followed with regard to total and cause-specific mortality.

\section{Exposure information}

The company files contained information on job title, start and end of each type of employment (month and year), and workplace. Job title and workplace characteristics made it possible to classify each person with regard to length of shiftwork with a high degree of certainty. The participants were grouped into the following exposure categories: never worked shifts (ie, dayworkers), shiftwork for $<5$ years, shiftwork for 5-9 years, shiftwork for 10-19 years, shiftwork for 20-29 years, and shiftwork for $\geq 30$ years.

For each person in the cohort, information about shiftwork exposure was available from the first date of employment.

\section{Shiftwork}

Typical job titles in shiftwork were barking, grinding, screening, boiling, bleaching, and paper manufacturing.

The shift schedules in the pulp and paper industry have varied little over time. In a continuous production process, a typical rotating three-shift schedule has traditionally been used to meet production requirements. Permanent night shifts have not been on a regular basis.

The shift schedules from the 1940s until the beginning of the 1950s were mainly slow rotating three-shift schedules. The first week was the morning shift, 0600 1400 from Monday to Saturday, the second week was an afternoon shift, 1400-2100 from Monday to Saturday, and the third week was a nightshift, 2100-0600 from Sunday to Friday. The length of the workday was normally 8 hours, but exceptions were made on weekends with reduced staff and limited production and with workdays of up to 12 or even 16 hours. Production was stopped for a couple of weeks during the summer holidays. The total workweek was 48 hours. During the 1950s a system called a "continuous production line" was introduced. A fourth shift was introduced to increase production. It was also intended to improve the shiftwork schedule.

Gradually from 1957 to 1972 a reduction in the workweek took place, from 48 to 40 hours.

A fifth shift was introduced to comply with legislation and to improve work conditions and to increase production. It was implemented in 1965 in one plant and in 1971 in the other. A typical rotating five-shift schedule at that time is shown in table 1.

In the late 1970s, the workweek was reduced to an average of 36 hours. This change led to the introduction of a sixth shift. Similar shift schedules were still in use in the 1980s and 1990s. A typical rotating six-shift schedule is shown in table 1 .

Table 1. Shift schedule in 1965-1977 and 1978-1998. (morning shift $=0600-1400$, afternoon shift $=1400-2200$, night shift $=2200-$ $0600, \mathrm{~h}=$ hours)

\begin{tabular}{|c|c|c|c|c|c|c|c|}
\hline \multicolumn{8}{|c|}{ Shift schedule } \\
\hline & Monday & Tuesday & Wednesday & Thursday & Friday & Saturday & Sunday \\
\hline \multicolumn{8}{|c|}{ 1965-1977 } \\
\hline Week 1 & Morning shift (8 h) & Morning shift (8 h) & Morning shift (8 h) & Morning shift (8 h) & Morning shift (8 h) & Morning shift (12 h) & Morning shift(12 h) \\
\hline Week 2 & Afternoon shift (8 h) & Afternoon shift (8 h) & Afternoon shift (8h) & Afternoon shift (8 h) & Afternoon shift (8 h) & Free day & Free day \\
\hline Week 3 & Night shift (8 h) & Night shift (8 h) & Night shift (8h) & Night shift (8 h) & Night shift $(8 \mathrm{~h})$ & Night shift (12 h) & Night shift \\
\hline Week 4 & Free day & Free day & Free day & Free day & Free day & Free day & Free day \\
\hline Week 5 & Free day & Free day & Free day & Free day & Free day & Free day & Free day \\
\hline \multicolumn{8}{|c|}{ 1978-1998 } \\
\hline Week 1 & Afternoon shift (8 h) & Afternoon shift (8 h) & Afternoon shift (8 h) & Afternoon shift (8 h) & Afternoon shift (8 h) & Afternoon shift (8 h) & Morning shift (12 h) \\
\hline Week 2 & Free day & Free day & Free day & Free day & Night shift (8h) & Night shift (8 h) & Night shift (12 h) \\
\hline Week 3 & Night shift (8 h) & Night shift (8 h) & Night shift (8 h) & Night shift (8 h) & Free day & Free day & Free day \\
\hline Week 4 & Morning shift (8 h) & Morning shift (8 h) & Morning shift (8 h) & Morning shift (8 h) & Morning shift (8 h) & Morning shift (8 h) & Free day \\
\hline Week 5 & Free day & Free day & Free day & Free day & Free day & Free day & Free day \\
\hline Week 6 & Free day & Free day & Free day & Free day & Free day & Free day & Free day \\
\hline
\end{tabular}




\section{Daywork}

Typical job titles for dayworkers included electrical and mechanical maintenance workers, laboratory workers, and cleaners.

A 48-hour workweek was the norm from 1919 to 1957. Gradually, from 1958 to 1972 a stepwise reduction in the workweek took place, from 48 to 40 hours.

\section{Follow-up}

The company files included the employees' personal identity numbers-a unique number assigned for personal identification purposes to all Swedish residents. Stringent efforts were made to ensure that the registered personal identity numbers were complete and valid.

The mortality of the cohort was monitored from 1 January 1952 to 31 December 2001 by linkage to the national Cause of Death Register. This register was computerized in 1952-the first year of the cohort follow-up.

We studied both total mortality and cause-specific mortality due to CHD, ischemic stroke (excluding hemorrhages), and diabetes. During the 50-year observation period, the assignment of diagnosis was based on five consecutive revisions of the International Classification of Diseases (ICD) - 1952-1957 the sixth, 19581968 the seventh, 1969-1986 the eighth , 1987-1996 the ninth, and 1997-2002 the tenth. [Detailed information is given in the appendix.]

Death due to a specific cause was established by the appearance of the relevant diagnosis on the death certificate as a primary or contributory cause of death. This information enabled the gathering of information on all diagnoses of interest. Diabetes, for example, is rarely cited as a primary cause of death.

\section{Statistical methods}

Mortality rates were expressed as the number of deaths (total or according to diagnosis) divided by the total time at risk for the relevant group. The participants could contribute to the time at risk within different shift-exposure categories. Thus a participant contributed to the time at risk within a specific shift-exposure category until he fulfilled the requirements for the next shift exposure category.

Mortality among the participants in different shiftexposure categories was compared with the corresponding mortality among dayworkers by calculating a relative rate together with a $95 \%$ confidence interval $(95 \%$ $\mathrm{CI})$. In order to take differences in the age distributions into account, direct standardized relative rates (SRR) were calculated based on weights derived from the unexposed group. The standardization was based on 5-year age groups. The $95 \%$ confidence intervals were computed on the assumption of a Poisson distribution (6). Two analyses were carried out, the first with the full material and the second essentially with occupationally active workers. In the first analysis, the follow-up period was as long as possible (ie, without restrictions concerning age or employment). In the second analysis, the length of follow-up was restricted to end at the age of 68 years. Workers usually retire at 65 years of age in Sweden. For persons who left their employment during the study period, the follow-up was terminated 4 years after the end of the employment, at the latest. Calendar time was taken into consideration by performing separate analyses for the time periods 1952-1975 and 1976-2001, respectively. A trend analysis was carried out by linear regression modeling (7) in order to assess the pattern of effects over exposure categories (years of shiftwork).

The study was approved by the research ethics committees of the Sahlgrenska University Hospital and the Karolinska Institute.

\section{Results}

Table 2 shows the number of workers and the accumulated time at risk by age at entry. Altogether $175 \mathrm{em}-$ ployed persons were younger than 15 years at entry. For these men, the median time of employment was 33 years. Altogether $69 \%$ of the workers were younger than 30 years when first employed.

Death due to any cause (total mortality) was not higher among the shiftworkers than among the dayworkers (SRR 1.02, 95\% CI 0.93-1.11) (table 3).

However, mortality due to CHD was $11 \%$ higher among the shiftworkers than among the dayworkers (SRR 1.11, 95\% CI 0.95-1.30). The risk was the most pronounced for those with $\geq 30$ years of shiftwork experience (SRR 1.24, 95\% CI 1.04-1.49). Duration of shiftwork was associated with an increased risk of CHD $\left[\mathrm{b}(\right.$ linear coefficient $)=16.4 \times 10^{-5}, 95 \%$ CI $13.2 \times 10^{-5}$ $\left.19.7 \times 10^{-5}\right)$.

A difference in mortality due to ischemic stroke was observed when all the shiftworkers were compared with the dayworkers (SRR 1.56, 95\% CI 0.98-2.51). The highest relative rate ratio was observed for those with the shortest shiftwork experience ( $<5$ years) with an SRR of 4.57 (95\% CI 1.58-13.21), although based only on four exposed cases. The SRR for mortality due to diabetes associated with shiftwork was 1.24 (95\% CI 0.91-1.70). After 20-29 years of employment as a shiftworker, the SRR for diabetes was 1.54 (95\% CI 0.93 2.57). The corresponding SRR was 1.22 (95\% CI 0.84 1.79) for workers with $\geq 30$ years of shiftwork. The risk of death due to diabetes as an underlying or contributory cause increased as the number of shift years increased 
$\left[\mathrm{b}(\right.$ linear coefficient $)=4.14 \times 10^{-5}, 95 \%$ CI $2.46 \times 10^{-5}$ $\left.5.81 \times 10^{-5}\right]$.

After restriction for length of follow-up to end at a maximum of 68 years of age [or at a maximum of 4 years after the termination of employment (ie, an age closer to exposure)], the number of exposed cases was smaller and the confidence intervals were wider. Apart from diabetes, the results were similar to those from the analysis of the full material. For diabetes, the SRR was 2.29 (95\% CI 0.97-5.40). Furthermore, the trend towards an increased risk of death due to diabetes with an increasing number of shift years was strengthened; the SRR for the shiftworkers exposed to 10-19 years, 20-29 years, or $\geq 30$ years of shiftwork was 1.41 (95\% CI $0.18-11.30), 1.92$ (95\% CI $0.50-7.32$ ), and 2.85 (95\% CI 1.15-7.08), respectively.

For all the studied outcomes, the SRR values comparing shiftworkers with dayworkers were similar between the two time periods, 1952-1975 and 1976-2001.

\section{Discussion}

This cohort study did not observe an increase in general mortality among shiftworkers as compared with dayworkers. However, we observed an increase in CHD mortality for the shiftworkers who had worked shifts for $\geq 30$ years. Increased mortality from ischemic stroke came close to statistical significance, and we observed a trend towards increased rates of death from diabetes with a longer duration of shiftwork exposure.

Our findings on general mortality are consistent with those of two previous studies $(4,5)$.

There is a considerable amount of published evidence for an association between shiftwork and CHD
Table 2. Cohorts and accumulated person-years by age at entry into shift- and daywork.

\begin{tabular}{lcccc}
\hline $\begin{array}{l}\text { Age at } \\
\text { entry }\end{array}$ & $\begin{array}{c}\text { Number } \\
\text { of } \\
\text { workers }\end{array}$ & $\begin{array}{c}\text { Person- } \\
\text { years of } \\
\text { follow-up } \\
\text { (N) }\end{array}$ & $\begin{array}{c}\text { Mean } \\
\text { duration of } \\
\text { follow-up } \\
\text { (years) }\end{array}$ & $\begin{array}{c}\text { Mean } \\
\text { duration of } \\
\text { employment } \\
\text { (years) }\end{array}$ \\
\hline 10-14 years & & & & \\
Dayworkers & 120 & 5137 & 42.8 & 25.0 \\
Shiftworkers & 55 & 2255 & 41.0 & 39.2 \\
15-19 years & & & & \\
Dayworkers & 1069 & 35803 & 33.5 & 16.6 \\
Shiftworkers & 722 & 23728 & 32.9 & 26.4 \\
20-24 years & & & & \\
Dayworkers & 584 & 17157 & 29.4 & 16.0 \\
Shiftworkers & 522 & 15422 & 29.5 & 23.2 \\
25-29 years & & & & \\
Dayworkers & 327 & 10290 & 31.5 & 22.4 \\
Shiftworkers & 347 & 9677 & 27.9 & 22.9 \\
30-34 years & & & & \\
Dayworkers & 263 & 7961 & 30.3 & 22.1 \\
Shiftworkers & 251 & 6857 & 27.3 & 22.1 \\
35-39 years & & & & \\
Dayworkers & 226 & 6209 & 27.5 & 20.2 \\
Shiftworkers & 179 & 4676 & 26.1 & 19.6 \\
40-44 years & & & & \\
Dayworkers & 196 & 5255 & 26.8 & 15.9 \\
Shiftworkers & 125 & 3408 & 27.3 & 17.3 \\
45-49 years & & & & \\
Dayworkers & 138 & 3497 & 25.3 & 13.3 \\
Shiftworkers & 86 & 2025 & 23.5 & 14.0 \\
50-54 years & & & & \\
Dayworkers & 106 & 2408 & 22.7 & 9.1 \\
Shiftworkers & 49 & 1019 & 20.8 & 9.9 \\
55-59 years & & & & \\
Dayworkers & 59 & 1262 & 21.4 & 6.1 \\
Shiftworkers & 18 & 421 & 23.4 & \\
All ages & & & & \\
Dayworkers & 3088 & 94979 & 30.8 & 17.5 \\
Shiftworkers & 2354 & 69488 & 29.5 & 23.1 \\
\hline & & & & \\
\hline
\end{tabular}

Table 3. Standardized relative ratio (SRR) for total mortality, coronary heart disease, stroke, and diabetes among the shiftworkers when compared with the dayworkers. (95\% Cl $=95 \%$ confidence interval)

\begin{tabular}{|c|c|c|c|c|c|c|c|c|c|c|c|c|c|}
\hline & \multicolumn{4}{|c|}{ Total mortality } & \multicolumn{3}{|c|}{ Coronary heart disease } & \multicolumn{3}{|c|}{ Ischemic stroke } & \multicolumn{3}{|c|}{ Diabetes } \\
\hline & $\begin{array}{l}\text { Cases } \\
\text { (N) }\end{array}$ & $\begin{array}{l}\text { Person- } \\
\text { years } \\
\text { (N) }\end{array}$ & $\mathrm{SRR}^{\mathrm{a}}$ & $95 \% \mathrm{Cl}$ & $\begin{array}{c}\text { Cases } \\
\text { (N) }\end{array}$ & $\mathrm{SRR}^{\mathrm{a}}$ & $95 \% \mathrm{Cl}$ & $\begin{array}{l}\text { Cases } \\
(\mathrm{N})\end{array}$ & $\mathrm{SRR}^{\mathrm{a}}$ & $95 \% \mathrm{Cl}$ & $\begin{array}{c}\text { Cases } \\
\text { (N) }\end{array}$ & $\mathrm{SRR}^{\mathrm{a}}$ & $95 \% \mathrm{Cl}$ \\
\hline $\begin{array}{l}\text { Dayworkers } \\
\text { Shiftworkers }\end{array}$ & 1090 & 94979 & . & . & 375 & . & . & 34 & . & . & 85 & $\cdot$ & . \\
\hline$<5$ years & 46 & 11117 & 0.99 & $0.65-1.50$ & 10 & 0.85 & $0.30-2.38$ & 4 & 4.57 & $1.58-13.21$ & 3 & 0.57 & $0.17-1.90$ \\
\hline$\geq 5-<10$ years & 40 & 5525 & 0.94 & $0.65-1.36$ & 14 & 0.97 & $0.56-1.67$ & 1 & 0.54 & $0.07-3.97$ & 3 & 0.99 & $0.31-3.22$ \\
\hline$\geq 10-<20$ years & 106 & 13476 & 0.93 & $0.76-1.14$ & 34 & 0.83 & $0.58-1.19$ & 5 & 1.76 & $0.68-4.57$ & 10 & 1.09 & $0.56-2.10$ \\
\hline$\geq 20-<30$ years & 168 & 16177 & 1.06 & $0.90-1.25$ & 54 & 1.02 & $0.77-1.36$ & 5 & 1.08 & $0.42-2.78$ & 18 & 1.54 & $0.93-2.57$ \\
\hline$\geq 30$ years & 400 & 23193 & 0.98 & $0.88-1.10$ & 175 & 1.24 & $1.04-1.49$ & 20 & 1.51 & $0.87-2.63$ & 39 & 1.22 & $0.84-1.79$ \\
\hline $\begin{array}{l}\text { All shiftworkers } \\
\text { versus dayworkers }\end{array}$ & s 760 & 69488 & 1.02 & $0.93-1.11$ & 287 & 1.11 & $0.95-1.30$ & 35 & 1.56 & $0.98-2.51$ & 73 & 1.24 & $0.91-1.70$ \\
\hline
\end{tabular}

a $A$ ll of the rates have been adjusted for age. 
(3). A possible association between shiftwork and stroke has not been systematically explored, but a Finnish epidemiologic study of socioeconomic inequalities in cardiovascular mortality found that shiftwork was the most influential cause of cerebrovascular death (8). CHD and stroke are both multifactorial diseases and share many risk factors.

Possible novel risk factors for atherosclerosis leading to stroke have been recently reviewed (9), and some of them are more prevalent for shiftworkers.

An unexpected finding in this study was the high relative rate of mortality due to stroke among the workers with short shiftwork experience ( $<5$ years). The result should be interpreted with caution since it is based on a small number of cases, and, therefore, the confidence intervals are wide. However, our finding raises the question of whether some persons are more susceptible to the deleterious effects of shiftwork. This finding could be due to the rapid appearance of signs of ill health for some shiftworkers who may consequently have stopped working shifts.

The association between shiftwork and diabetes has been the subject of investigation in only a few published studies. Kawachi et al (10) reported an increased prevalence of diabetes in relation to years of nightwork in a cohort study of nurses. In a cross-sectional Japanese study (11) it was observed that diabetes was more common among three-shift workers than among dayshift workers. Another recently published cross-sectional study from Japan did not find differences between shiftworkers and dayworkers (12). Nor did an 8-year followup study of employees in an electrical company in Japan show any excess risk of diabetes among rotating shiftworkers (13).

Unfortunately, no preemployment medical examinations were made in this pulp and paper cohort. During the first years of shiftwork, sleep problems, disruptions of circadian regulations, and social inconvenience can result in some people reverting to daywork and, therefore, enhance the general health parameters of those remaining in shiftwork (14).

The homogeneous socioeconomic status of the study population is a major strength. It was achieved through the restriction of the participants to blue-collar workers. We also obtained high-quality data on shiftwork exposure by using well-kept company records containing detailed information. Very few participants were excluded due to an uncertain occupational history. The company workforce has been very stable. The mean duration of employment among shiftworkers was 23.1 years, and among dayworkers it was 17.5 years. In our material, it was very unusual for shiftworkers to be "transferred" to daywork within the company. This was done in only 16 individual cases. However, we do not have details of the occupational history for periods of employment by other companies, and therefore it is pos- sible that shiftworkers worked shifts for longer periods than we had recorded. Another consequence is that some of the dayworkers may have been shiftworkers within other companies (which, in turn, would bias our estimated relative rates towards the null).

The quality of the Cause of Death Register in Sweden is high, and it is unlikely that a differential misclassification would have occurred for different diagnoses between shiftworkers and dayworkers in this cohort. There were no main differences in the results when the specific causes of death for CHD and stroke were studied irrespective of whether only the primary cause of death or a combination of primary and contributory causes of death was used in the analysis.

A subset $(\mathrm{N}=1324)$ of the current study population took part in the WOLF (work, lipids and fibrinogen) study (15) regarding the relationship between the work environment and risk factors for CHD. This study was carried out between 1996 and 1997 (ie, coinciding with only the last part of the observation period of the current study). The prevalence of smoking was similar for the shiftworkers and dayworkers (14.4\% versus $16.0 \%)$. The prevalence of exercise was also found to be similar for the shiftworkers and dayworkers. When the shiftworkers were compared with the dayworkers, the prevalence of several cardiovascular and metabolic risk factors (high triglycerides, low high-density lipoprotein cholesterol and increased abdominal obesity) was observed to be increased among the shiftworkers (15). Furthermore, these differences remained also after adjustment for age, socioeconomic group, physical activity, current smoking, low social support, and job strain. Although based on cross-sectional data, this observation lends some support to the notion that the observed relationship between shiftwork and CHD, diabetes, and stroke may be of a causal nature. We cannot, however, exclude the possibility that potential confounding factors may have been greater in the more distant past.

In order to study the potential influence from confounding from smoking, we compared the mortality due to lung cancer between the shiftworkers and dayworkers in our cohort. The age-standardized relative rate was 0.87 (95\% CI $0.47-1.25)$. Thus it seems unlikely that confounding from smoking biased our relative rates away from the null.

To summarize, this study did not observe any increased general mortality for shiftworkers as compared with dayworkers. However, our results indicate an increased mortality from CHD for shiftworkers with the longest exposure time. We also observed a trend towards increasing mortality due to diabetes with an increasing number of shift years and a higher mortality due to ischemic stroke among shiftworkers. Additional studies on the potential association between shiftwork and outcomes such as stroke and diabetes are needed. 


\section{Acknowledgments}

This study was supported by a grant from the Swedish Work and Environmental Fund. The authors would like to express their gratitude to the participants and to the supportive management of MoDo.

\section{References}

1. Åkerstedt T. Shift work and disturbed sleep/wakefulness. Occup Med (Lond) 2003;53(2):89-94.

2. Costa G. The impact of shift and nightwork on health. Appl Ergon 1996;27:9-16.

3. Bøggild H, Knutsson A. Shiftwork, risk factors and cardiovascular disease [review]. Scand J Work Environ Health 1999; 25(2):85-99.

4. Taylor P, Pocock S. Mortality of shift and day workers 195668. Br J Ind Med 1972;29:201-7.

5. Bøggild H, Suadicani P, Hein H, Gyntelberg F. Shiftwork, social class and ischaemic heart disease in middle aged and elderly men; a 22 year follow up in the Copenhagen male study. Occup Environ Med 1999;56:640-5.

6. Ahlbom A. Biostatistics for epidemiologists: Boca Raton (CA): Lewis Publishers; 1993.

7. Rothman K. Modern epidemiology. Boston/Toronto: Little, Brown and Company; 1986.
8. Virtanen S, Notkola V. Socioeconomic inequalities in cardiovascular mortality and the role of work: a register study of Finnish men. Int J Epidemiol 2002;31:614-21.

9. Goerlick P. Stroke prevention therapy beyond antithrombotics: unifying mechanisms in ischaemic stroke pathogenesis and implications for therapy, an invited review. Stroke 2002; 33:862-75.

10. Kawachi I, Colditz G, Stampfer M, Willet W, Manson J, Speizer F, et al. Prospective study of shiftwork and risk of coronary heart disease in women. Circulation 1995;92:317882.

11. Mikuni E, Ohoshi T, Hayashi K, Miyamura K. Glucose intolerance in an employed population Tohoku J Exp Med 1983;141 Suppl:251-6.

12. Nagaya T, Yoshida H, Takahashi H, Kawai M. Markers of insulin resistance in day and shift workers aged 30-59 years. Int Arch Occup Environ Health 2002;75(8):562-8.

13. Kawakami N, Araki S, Takatsuka N, Shimizu H, Ishibashi H. Overtime, psychosocial working conditions, and occurrence of non-insulin dependent diabetes mellitus in Japanese men. J Epidemiol Community Health 1999;53:359-63.

14. Härmä M. Individual differences in tolerance to shiftwork: a review. Ergonomics 1993;36:101-9.

15. Karlsson BH, Knutsson AK, Lindahl BO, Alfredsson LS. Metabolic disturbances in male workers with rotating threeshift work: results of the WOLF study. Int Arch Occup Environ Health 2003;76:424-30.

Received for publication: 5 February 2004

\section{Appendix}

\section{Cause-specific mortality}

\begin{tabular}{|c|c|}
\hline Outcome & ICD codes a \\
\hline \multicolumn{2}{|c|}{ Coronary heart disease } \\
\hline $\begin{array}{l}1952-1957 \\
1958-1967 \\
1968-1986 \\
1987-1996 \\
1997-2001\end{array}$ & $\begin{array}{l}4200,4201,4202,4203,4209 \\
4200,4201,4202 \\
410,411,412,, 413,414 \\
410,411,412,413,414 \\
\mathrm{I} 20, \mathrm{I} 21, \mathrm{I} 22, \mathrm{I} 23, \mathrm{I} 24\end{array}$ \\
\hline \multicolumn{2}{|l|}{ Stroke ${ }^{b}$} \\
\hline $\begin{array}{l}1952-1957 \\
1958-1967 \\
1968-1986 \\
1987-1996 \\
1997-2001\end{array}$ & $\begin{array}{l}3320,3321,332 \\
332 \\
432,433,434 \\
433,434 \\
163,164\end{array}$ \\
\hline \multicolumn{2}{|l|}{ Diabetes } \\
\hline $\begin{array}{l}1952-1957 \\
1958-1967 \\
1968-1986 \\
1987-1996 \\
1997-2001\end{array}$ & $\begin{array}{l}260 \\
260 \\
250 \\
250 \\
\mathrm{E} 10, \mathrm{E} 11, \mathrm{E} 12, \mathrm{E} 13, \mathrm{E} 14\end{array}$ \\
\hline
\end{tabular}

a ICD = International Classification of Diseases.

${ }^{\mathrm{b}}$ All specifically defined hemorrhages in the death certificate were excluded. 